\title{
Special issue on cell and molecular biology of purinergic signalling: an introduction
}

\author{
Geoffrey Burnstock • Paul A. Insel • \\ Francesco Di Virgilio
}

Published online: 4 April 2012

(C) Springer Science+Business Media B.V. 2012

The rationale for this special issue was that while pharmacologists, physiologists and a growing number of clinicians recognise the importance of ATP as an intercellular signalling molecule, which appeared early in evolution, most cell biologists and many biochemists seem to be unaware of this fundamental signalling molecule. Despite the overwhelming evidence that ATP has a role as a messenger and the formal identification of plasma membrane receptors for ATP, extracellular ATP is often regarded as a 'tool' rather than a physiological mediator of cell-to-cell communication, i.e. ATP is used to raise intracellular calcium to investigate intracellular pathways and events.
In this issue, we have assembled articles that describe the multiple roles of extracellular ATP and P2 receptors in key biological events, including embryonic development, stem cell and hematopoietic cell differentiation, glia and neuronal survival, apoptosis, phagocytosis, chemotaxis and sensation. We have also sought to provide readers with an overview regarding ATP synthesis, storage and release and descriptions of membrane receptors for ATP and other extracellular nucleotides and of nucleotide-consuming ectoenzymes. We hope that this special issue will inspire new experiments that reveal further insights regarding nucleotides in cellular regulation.

\footnotetext{
G. Burnstock $(\bowtie)$

Autonomic Neuroscience Centre, Royal Free and University

College Medical School,

Rowland Hill Street,

London NW3 2PF, UK

e-mail: g.burnstock@ucl.ac.uk

\section{P. A. Insel}

Department of Pharmacology, University of California,

San Diego, 9500 Gilman Drive La Jolla,

CA 92093-0636, USA

F. Di Virgilio

Department of Experimental

and Diagnostic Medicine, University of Ferrara,

via L. Borsari 46,

Ferrara 44100, Italy
} 